\title{
Scientific Opinion: Improving the Definition of Grape Phylloxera Biotypes and Standardizing Biotype Screening Protocols
}

\author{
Astrid Forneck, ${ }^{1 *}$ Kevin S. Powell, ${ }^{2}$ and M. Andrew Walker ${ }^{3}$
}

\begin{abstract}
Grape phylloxera biotypes are defined by their specific performance on, or preference for, a particular host (e.g., feeding on a particular rootstock). Numerous studies have phenotyped phylloxera biotypes, particularly with regard to their performance on various hosts, but the results are difficult to compare because there is neither a homogenous nomenclature nor a standardized protocol for phenotyping. To improve communication within the scientific community, we offer a simplified phylloxera biotype classification to allow clear data interpretation and effective communication. We also introduce the standard techniques employed for phylloxera phenotyping and discuss their advantages and disadvantages.
\end{abstract}

Key words: aggressivity, biotype, Daktulosphaira vitifoliae, grapevine, host plant, rootstock

The term "biotype" was first applied to grape phylloxera last century (Printz 1937). However, grape phylloxera ( $D a$ ktulosphaira vitifoliae Fitch) biotypes did not become well known until after the outbreak of a previously unknown phylloxera strain capable of feeding, developing, and producing tuberosities on the Vitis vinifera $\times V$. rupestris hybrid rootstock AXR\#1 in the late 1980s (Granett et al. 1983). This biotype, commonly known as Biotype B, caused substantial economic losses in California. In general, when the phylloxera literature refers to biotypes, it implies a specific performance on, or preference for, a particular host as measured by survival, development, and individual life stages resulting in growth of populations or individual insects. Although host suitability and intrinsic performance of insects are not synonymous (Singer 1986), the term is often used to describe the aggressiveness of a phylloxera strain (King and Rilling 1991, Corrie et al. 1997, Anonymous 2014). The term "biotype" has been used historically for strains of insect pests that vary in their response to hosts (Claridge and Den Hollander 1983) and variants are often classified using numbers or letters. The genetic background of variants is often not clearly defined and the phenotypic variation could be based on allelic genotypes, or at the level of an individual or population (Sandström and Pettersson 1994, Downie 2010).

\footnotetext{
${ }^{1}$ University of Natural Resources and Life Sciences, Vienna, Division of Viticulture and Pomology, Konrad-Lorenz Str. 24, A-3430 Tulln, Austria; ${ }^{2}$ Department of Economic Development, Jobs, Transport \& Resources, Biosciences Research Division, 124 Chiltern Valley Road, Rutherglen, Victoria, 3685 Australia; and ${ }^{3}$ University of California, Davis, Department of Viticulture and Enology, Davis, CA 95616.

*Corresponding author (astrid.forneck@boku.ac.at; tel: +43 1476543441)

Acknowledgments: Financial support was provided by the OECD (Fellowship grant TAD/CRP JA00079310) to AF.

Manuscript submitted Nov 2015, revised Apr 2016, May 2016, accepted May 2016

Copyright $(2016$ by the American Society for Enology and Viticulture. All rights reserved.

doi: 10.5344/ajev.2016.15106
}

Over the last 30 years, numerous studies have phenotyped phylloxera, particularly in regard to its performance on various hosts, by assessing insect survival, development, and growth. The physiological response of hosts in the form of gall production as nodosities and tuberosities on roots or galls on leaves has been also used (Powell et al. 2013). The results are sometimes difficult to interpret and compare because of the lack of homogenous nomenclature and a standardized protocol for phenotyping. We offer a simplified phylloxera biotype classification here to facilitate easier interpretation and comparison of results.

Phylloxera phenotypes. The terms "aggressiveness" and "virulence" are used inconsistently in the literature to describe phylloxera biotypes and strains, their performance (rate of development and reproduction) on different hosts and in different environments, and the damage they cause to hosts (e.g., Granett et al. 2001, Herbert et al. 2010). Furthermore, the term "biotype" is sometimes used for mixed populations of similarly-performing strains, rather than for a specific genotype. In addition, aggressiveness is often measured using life table parameters, which essentially assess the insect's developmental characteristics, rather than its impact on the host plant (Granett et al. 1985). Generally, phylloxera development is strongly dependent on the environment (host, abiotic factors, etc.). Despite known genetic and physiological differences among populations, comparative studies of morphology have yielded no evidence that grape phylloxera strains can be distinguished using morphological characteristics (Forneck and Huber 2009). Defined protocols for phylloxera phenotyping are needed to further promote research into the development of biomarkers associated with differences in phylloxera aggression.

Phylloxera genotypes. Over the past 30 years, the existence of different phylloxera strains has become more apparent because of differences in performance on a range of Vitis genotypes. New strains can evolve, as with Biotype B (Granett et al. 1985), which overcame the partially-resistant AXR\#1 
rootstock genotype (Sullivan 1996). A wide range of phylloxera strains has been reported in Europe (Song and Granett 1990, Forneck et al. 2001b, Yvon and Peros 2003), Australasia (King and Rilling 1985, Corrie et al. 1997, 2002, Umina et al. 2007), Canada (Stevenson 1970), South Africa (De Klerk 1979), USA (Williams and Shambaugh 1988, De Benedictis and Granett 1992), and China (Du et al. 2008). It is not possible to accurately characterize the distribution of all strains in different countries without a standard genetic basis, set of protocols for strain identification, phenotyping protocol, and established links between phenotype (performance and effects on the host) and genotype. However, it is likely that the two Australian strains G1 and G4 (subsequently defined as superclones [Umina et al. 2007]), both with accurate genetic descriptions, represent strains that have not been found in any other grapegrowing country (Powell et al. 2013). To better define phylloxera genotypes, a standardized genotypic protocol proposed by the ISHS Phylloxera Work Group in 2014 defines and names phylloxera genotypes suitable for comparative studies (Forneck et al. 2015). An open database of phylloxera genotypes (PHYLLI; https://www.dnw.boku.ac.at/wob/ international-phylloxera-genotype-database/) is now available.

An updated concept of biotypes and aggression in grape phylloxera. Currently, phylloxera biotypes are classified according to their performance on, and damage to (nodosity, tuberosity), a particular Vitis host for field clones, and lineages are characterized by their phenotype. Superclones are strains that constitute 40 to $60 \%$ of the population in a region (Vorburger et al. 2003) and that have higher fitness and damage potential on a general set of host plants (Powell et al. 2013).
Proposed biotype classification. Phenotyping of phylloxera strains should include both the life table parameters of the phylloxera strain under study and evaluation of host plant responses: whether root feeding induces either nodosities (organoid galls on root tips), tuberosities (galled tissue on mature roots), both, intermediate galls on mature roots (pseudotuberosities) (Powell and Korosi 2014), or root necrosis. Host plant response by leaf feeding strains can be evaluated according to whether leaf feeding induces a complete or incomplete gall (with reproducing phylloxera), incomplete/partial galls (without reproducing phylloxera), or leaf necrosis. Any feeding and growth of phylloxera requires a gall providing nutritive tissue and resources to allow the insect to develop to the adult stage and subsequently reproduce. We suggest that the term "biotype" be used as a category designating shared phenotypic traits. In practice, with effective viticultural management, phylloxera strains that are equal in their ability to establish and develop on a particular host plant consequently belong to the same biotype group (see below). The degree of aggression is measured as the rate of life-stage development and subsequent population increase on either type of gall, and can vary among phylloxera strains within the biotype group. A biotype classification based on a review of the existing literature is proposed, with parameters for classification based on phylloxera and host plant interactions (Table 1).

Biotype A group includes strains showing superior performance on nodosities and tuberosities on $V$. vinifera roots and limited performance on nodosities on rootstock roots derived from crosses between American Vitis species (Granett et al. 1985, King and Rilling 1985).

\begin{tabular}{|c|c|c|c|c|c|c|c|c|c|c|}
\hline \multirow{2}{*}{$\begin{array}{l}\text { Biotype/ } \\
\text { Feeding tissue } \\
\text { A } \\
\text { Root } \\
\text { Leaves } \\
\end{array}$} & \multicolumn{3}{|c|}{ Vitis vinifera } & \multicolumn{3}{|c|}{$\begin{array}{l}\text { Rootstocks and } \\
\text { hybrids } \\
\text { (V. vin. x American } \\
\text { Vitis species }\end{array}$} & \multicolumn{3}{|c|}{$\begin{array}{c}\text { Rootstocks } \\
\text { (American Vitis } \\
\text { species) }\end{array}$} & \multirow{2}{*}{$\begin{array}{c}\text { Reference } \\
\text { Granett et al. 1985, King and Rilling } 1985\end{array}$} \\
\hline & $\mathrm{T}$ & $\begin{array}{l}N \\
-\end{array}$ & - & $\mathrm{t}$ & $\begin{array}{l}\mathrm{n} \\
\mathrm{G}\end{array}$ & - & - & $\begin{array}{l}n \\
G\end{array}$ & - & \\
\hline $\begin{array}{l}\text { B } \\
\text { Root } \\
\text { Leaves }\end{array}$ & $t$ & n & & $\mathrm{T}$ & $\begin{array}{l}\mathrm{N} \\
-\end{array}$ & & - & n & - & Granett et al. 1985 \\
\hline $\begin{array}{l}\text { C } \\
\text { Root } \\
\text { Leaves }\end{array}$ & - & $\begin{array}{l}\mathrm{n} \\
-\end{array}$ & - & $\mathrm{T}$ & $\begin{array}{l}N \\
G\end{array}$ & $\mathrm{P}$ & - & $\begin{array}{l}N \\
G\end{array}$ & $\mathrm{P}$ & $\begin{array}{l}\text { King and Rilling 1985, Forneck et al. } \\
2001 \mathrm{a} \text {, Kocsis et al. } 2002\end{array}$ \\
\hline $\begin{array}{l}\text { D } \\
\text { Root } \\
\text { Leaves } \\
\end{array}$ & $t$ & $\begin{array}{l}\mathrm{n} \\
- \\
\end{array}$ & - & - & $\begin{array}{l}\mathrm{N} \\
?\end{array}$ & - & - & $\begin{array}{l}N \\
G\end{array}$ & - & $\begin{array}{l}\text { Kellow et al. } 2002 \\
\text { Corrie and Hoffmann } 2004\end{array}$ \\
\hline $\begin{array}{l}\text { E } \\
\text { Root } \\
\text { Leaves }\end{array}$ & $\mathrm{T}$ & $\begin{array}{l}\mathrm{N} \\
- \\
\end{array}$ & - & $\mathrm{T}$ & $\begin{array}{l}\mathrm{N} \\
-\end{array}$ & $?$ & $\mathrm{~T}$ & N & $\mathrm{P}$ & Powell and Krstic 2015 \\
\hline $\begin{array}{l}\mathbf{F} \\
\text { Root } \\
\text { Leaves } \\
\end{array}$ & $\mathrm{T}$ & $\begin{array}{l}\mathrm{N} \\
\mathrm{G}\end{array}$ & - & $?$ & $\begin{array}{l}? \\
?\end{array}$ & $?$ & $?$ & $\begin{array}{l}n \\
\mathrm{G}\end{array}$ & $?$ & $\begin{array}{l}\text { MA Walker, personal communication, } \\
2016\end{array}$ \\
\hline $\begin{array}{l}\text { G } \\
\text { Root } \\
\text { Leaves }\end{array}$ & $?$ & $\begin{array}{l}? \\
\mathrm{G}\end{array}$ & $?$ & $?$ & $\begin{array}{l}N \\
G\end{array}$ & $?$ & - & $\begin{array}{l}N \\
G\end{array}$ & $?$ & Forneck et al. 2016 \\
\hline
\end{tabular}


Biotype B group includes strains showing superior performance on nodosities and tuberosities on the roots of rootstocks derived from American Vitis species crossed with $V$. vinifera (e.g., AXR\#1) and limited performance on nodosities on the roots of rootstocks derived from crosses between American species (Granett et al. 1985).

Biotype $C$ group includes strains showing superior performance on nodosities and pseudotuberosities on the roots of rootstocks derived from American Vitis species (e.g., T5C, 101-14 Mgt, C3309) and reduced ability to establish on $V$. vinifera roots (King and Rilling 1985, Forneck et al. 2001a, Kocsis et al. 2002).

Biotype D group includes strains originating on leaves of susceptible American Vitis species and rootstocks derived from American Vitis species with reduced ability to establish nodosities on the roots of rootstock or nodosities and tuberosities on $V$. vinifera roots (Downie et al. 2000, Kellow et al. 2002, Vidart et al. 2013).

Biotype E group includes strains showing superior performance of nodosities and tuberosities on susceptible $V$. vinifera roots, on nodosities and pesudotuberosities on the roots of some rootstocks derived from crosses between American Vitis species, and on rootstock roots derived from crosses between American Vitis species and $V$. vinifera (Powell and Krstic 2015, Trethowan and Powell 2007).

Biotype F group includes strains showing superior performance on both leaves and roots of $V$. vinifera and reduced performance on rootstock roots (MA Walker, personal communication, 2016).

Biotype $G$ group includes strains showing superior performance on nodosities and leaves of rootstocks derived from American Vitis species (e.g., T5C, 101-14 Mgt, C3309) and superior performance on leaves of $V$. vinifera, but reduced ability to establish nodosities and tuberosities on roots of $V$. vinifera (Forneck et al. 2016).

Current worldwide phylloxera biotype status. In Europe, most phylloxera strains screened to date belong to the Biotype $\mathrm{C}$ group, with occasional occurrences of Biotype A and Biotype F (e.g., Forneck et al. 2001b, Kocsis et al. 2002, Powell et al. 2013, A. Forneck, personal communication, 2015). However, very few strains have been characterized and more information is needed. In Australia, the most widely distributed strains identified belong to the Biotype A group, including the two superclones G1 and G4, although among the strains tested, some fit into the Biotype B, D, or E groups (Umina et al. 2007, KS Powell, personal communication, 2015). The geographic dominance of Biotype A in Australia may be the result of growing mainly own-rooted $V$. vinifera in this country. In California, strains of Biotypes A, B, C, and D have been found with shifting ratios over time (e.g., Granett et al. 2001). In Uruguay, Brazil, and Peru, Biotype A and F group strains have been found (Bao et al. 2015).

Although potential damage and genetic diversity of phylloxera strains is high, no convincing evidence has been provided for a single specific phylloxera strain being responsible for Vitis decline. The two superclones that singularly infest and kill own-rooted $V$. vinifera vines relatively rapidly in Aus- tralia are an exception to this observation. It is likely that such specific interactions are not known in other viticulture regions of the world because of the generally high diversity of strains that exist in vineyards and even on single vines, inconsistent procedures for identifying aggression and respective damage potential, and limited or reduced awareness that phylloxera is a potential cause of vineyard decline.

Proposed phylloxera biotyping protocols. A variety of methods have been used to study interactions between grape phylloxera and Vitis hosts including excised roots (Granett et al. 1985, 1987, De Benedictis and Granett 1993, De Benedictis et al. 1996, Makee et al. 2004), in vitro propagation (Pelet et al. 1960, Askani and Beiderbeck 1991, Forneck et al. 1996, Grzegorczyk and Walker 1998, Kellow et al. 2002), whole plants in plastic tubes (Yvon and Leclant 2000, Forneck et al. 2001a), whole potted plants (Boubals 1966, Ramming 2010, Herbert et al. 2010, Pavloušek 2012), and field-grown grapevines (Boubals 1966, Porten and Huber 2003, Trethowan et al. 2007). Each technique has technical advantages and disadvantages and may not provide equal or comparable results. Because of the economic importance of phylloxera root-feeding biotypes, we focus on presenting and discussing bioassays for root-feeding biotypes. Bioassays for leaf-feeding phylloxera exist (whole plant assays using aseptic dual culture, potted and caged under controlled environmental conditions or on caged or clipped leaves of field-grown plants), but are not described in detail here.

Here we propose standard procedures for biotype maintenance and screening of root-feeding phylloxera according to scientific standards aimed at reproducibility and feasibility. As there are several ways to conduct biotype screening and because phylloxera-host plant interactions may differ depending on the specific protocol used, a generic standard for each bioassay type is described.

Excised root bioassay. The excised root bioassay has been used widely as a rootstock screening system for several decades. It has the advantage of allowing comparative studies of phylloxera life-stage development, but the disadvantage of using excised plant material, which may affect secondary metabolite response, and hence the interaction between phylloxera and its host. The standard we suggest is based on a modified method of Granett et al. (1983) as follows:

Excise $V$. vinifera lignified roots from mature plants and cut into 70 to $80 \mathrm{~mm}$ long pieces, with a root diameter of 10 to $15 \mathrm{~mm}$. Dip roots in Ridomil fungicide at the rate of 7.3 g per $3 \mathrm{~L}$ water to deter fungal attack and then rinse three times in sterile water to remove excess fungicide residue. Air-dry root pieces aseptically in a laminar flow cabinet under UV light. Place dried root pieces on a filter paper-lined $90 \times 25 \mathrm{~mm}$ petri dish. Wrap both ends of the roots in cotton wool and moisten daily with sterile distilled water. Place 20 phylloxera eggs sourced from a single clonal lineage on each root piece with a fine soft paintbrush. Use a minimum of 10 replicates of each rootstock/phylloxera biotype combination. Seal petri dishes with Vitifilm or similar clingwrap to prevent phylloxera escaping and keep in the dark at constant temperature (growth room set at $25 \pm 2{ }^{\circ} \mathrm{C}$ ) for eight weeks. 
Record phylloxera survival and development weekly. Ensure removal of fungal infestation by judicious use of $70 \%$ ethanol on fungal hyphae at regular weekly intervals, taking care to avoid contact with phylloxera as ethanol can reduce phylloxera survival.

In vitro bioassay. Aseptic dual culture systems allow finetuned host-parasite interaction studies and detailed analysis of incompatible or compatible interactions. They can also be used to produce plant tissue suitable for further gene expression, microscopic, or metabolomic studies. The system has also been used to study phylloxera biotypes, since all Vitis species root well in vitro and provide optimized host conditions for both root- and leaf-feeding phylloxera. The system can be run under quarantine conditions all year round. The disadvantages are the time required, cost, and the potential contamination risk of the cultures. The standard we suggest is based on the method used by Forneck et al. (1996, 2001c) as follows:

Micropropagated green cuttings were pre-rooted in halfstrength Murashige \& Skoog medium and transferred into culture vessels partially filled with medium, poured with a sloped surface so that about half of the vessel's base is covered. After 14 days of growing, the vessels are returned to an upright orientation to promote root growth toward the mediafree side of the vessel. Between 10 and 50 phylloxera eggs (depending on the size of the vessel) are surface-sterilized and spread over the roots with an autoclaved fine paintbrush or pipette. Phylloxera first instars will start feeding immediately after hatching and galls form one to two dpi (days post inoculation). Environmental conditions for aseptic dual culture should be set at 22 to $25^{\circ} \mathrm{C}$ to reduce condensation in the vessel. If this cannot be achieved, an autoclaved cloth can absorb condensation water. Dual aseptic culture has been achieved in a range of vessels from petri dishes to $2 \mathrm{~L}$ jars. Phylloxera development can be recorded weekly, and stages and galls can be marked with a pen to track molting and survival. This system also allows leaf-galling phylloxera to be observed in real-time, since galls rarely close entirely under in vitro conditions.

In planta bioassay. An in planta bioassay system uses whole plants, with no induced effects caused by root excision, and is performed within cages to prevent phylloxera spread and migration. This bioassay has been introduced in several variations, of which we suggest either the bottle-system (Forneck et al. 2001b) or the potted trial with root enclosures (Korosi et al. 2007). To have comparable data, we suggest calibrating the phylloxera population data and plant responses (nodosities, pseudotuberosities, and tuberosities) in relation to the root biomass, which depends on the pot/vessel chosen.

The advantage with a potted trial is that root enclosures allow damage and phylloxera abundance to be assessed at the end of the trial with limited sample sorting. The advantages of the bottle method include the ability to observe root development/damage without disturbance, limited space requirements, and the ability to easily insect-proof the system to limit migration. The methods we recommend are a modified version of Korosi et al. (2007) and Forneck et al. (2001b), respectively, that runs the assay at $25 \pm 2{ }^{\circ} \mathrm{C}$ using a $16 \mathrm{hr}$ photoperiod.

Potted bioassay with root enclosures. Twenty phylloxera eggs are placed on a single lignified root piece $(1.5$ to $4.0 \mathrm{~mm}$ diam) on the root system of the potted vine and wrapped in $50 \mu \mathrm{m}$ mesh with Tanglefoot insect trap applied around the enclosure to prevent phylloxera escape. Repot the infested vines and place in a mesh bag $(50 \mu \mathrm{m}$ mesh) tied at the trunk of the vine and sealed with Tanglefoot to prevent phylloxera cross-contamination between pots. Keep plants under controlled conditions for eight weeks. At harvest, carefully wash root pieces, collect the washing, and examine for phylloxera life stages and assess root damage by counting tuberosities, pseudotuberosities, and nodosities (Korosi et al. 2007).

Bottle bioassay. Bottles are constructed from plastic $2 \mathrm{~L}$ soda bottles and fit with an insect-proof silk-screen baffle to allow airflow and humidity control. No drainage holes are required. The soil consists of a 3:2 mix of peat moss and soil mix (1:1:2 sand/loam/fir bark). Rooted green or dormant cuttings are planted in $1000 \mathrm{~mL}$ soil and irrigated with $200 \mathrm{~mL}$ water. Twenty eggs are placed on a moistened filter paper, which is then rolled into a tube and inserted deep into the soil. The first interaction can be observed three dpi. Keep plants under controlled conditions for two generations of phylloxera (eight weeks). Collect data for each generation on the visible root area adjacent to the bottle's surface. After harvest, the entire root system can be recovered to collect data on nodosities and tuberosities (Forneck et al. 2001a).

In-field bioassay. In-field bioassays are best used where single biotypes exist, although in some instances they can be used to test rootstocks where mixed biotypes occur (Trethowan and Powell 2007). There are two methods of biotype assessment, root and emergence trap assessment, that can be used either alone or in combination. If conducted throughout the season, root assessment monitors all phylloxera life stages while emergence traps monitor phylloxera dispersive stages, first instar, and adult alates. Bioassays can be conducted in areas in which a natural infestation of phylloxera is present or, if feasible, in a quarantined area where field inoculation is allowed.

In-field root bioassay. Phylloxera abundance on grapevine roots is best quantified over one to three successive seasons, in early- to midsummer when phylloxera life stage activity peaks and all life stages may be present. Assessing relative phylloxera abundance on roots can be conducted in a destructive or nondestructive manner. For the destructive method, 2 to $8 \mathrm{~g}$ dry weight root samples, including both lignified and non-lignified roots, are excised from the sample vine (10 to 20 sample vines are recommended per treatment). The excised root can then either be examined directly under a dissecting microscope or washed carefully and then examined, to determine the number of each phylloxera life-stage and the number of nodosities, pseudotuberosities, and tuberosities. Samples should be collected at three-week intervals. The roots are then oven-dried at $70^{\circ} \mathrm{C}$ for $48 \mathrm{hr}$ and weighed to quantify root dry weight and the insect/root ratio determined (Powell et al. 2003). 
In field emergence trap bioassay. Phylloxera abundance is best monitored in early- to midsummer when phylloxera activity is at its peak using plastic emergence traps over one to three successive seasons. These traps consist of 3 to $5 \mathrm{~L}$ translucent plastic bowls, inverted and placed $10 \mathrm{~cm}$ from the sample vine trunk (10 to 20 sample vines are recommended per treatment). Traps should be secured adjacent to vine trunks with three metal tent pegs (Powell et al. 2009). Traps are rinsed with tap water prior to placement to provide a film of condensate, which effectively traps emerging phylloxera dispersive life-stages. Trapped insects are collected at three-week intervals post-placement by removing the pegs, inverting, and washing with $70 \%$ ethanol into plastic vials. Trap samples are then examined using a low-power binocular microscope. Emergent phylloxera life-stages, consisting of first instar nymphs and winged alates, are recorded.

\section{Conclusion}

When choosing a bioassay for biotyping root-feeding phylloxera, one should consider that all bioassays presented here, with the exception of the excised root bioassay, promote nodosity-, tuberosity-, and pseudotuberosity-based feeding with a whole-plant response. In contrast, the excised root bioassay only allows testing of strains that feed on tuberosities and pseudotuberosities. We suggest using the excised root bioassay in combination with any lab-based bioassay to biotype phylloxera. Biotyping in the field is occassionally done using destructive or non-destructive techniques with root bioassays and/or emergence trap bioassays. Screening of field sample strains for their performance on leaves requires a bioassay with whole-plant response and is mostly done using the bottle bioassay, but potentially could also be conducted in the field. Although field conditions are difficult to control (e.g., climatic and edaphic), field bioassays can also be used to study the impact of phylloxera biotypes on whole-plant performance and grape yield. For standardization purposes and to ensure precise experimental screening conditions, we strongly suggest that phylloxera be selected from single-founder lineages and that a range of insect growth and development parameters (survival rate, fecundity, instar development time) be assessed. Ideally, standard biotypes should be co-screened as standards for comparison.

\section{Literature Cited}

Anonymous. 2014. Scientific opinion on the risk to plant health posed by Daktulosphaira vitifoliae (Fitch), in the EU territory, with the identification and evaluation of risk reduction options. EFSA J 12:3678.

Askani A and Beiderbeck R. 1991. In vitro propagation of Daktulosphaira vitifolii Shimer (Homoptera: Phylloxeridae) on shoot and root cultures of a Vitis hybrid. Vitis 30:223-232.

Bao LV, Scatoni IB, Gaggero C, Gutiérrez L, Monza J and Walker MA. 2015. Genetic diversity of grape phylloxera leaf-galling populations on Vitis species in Uruguay. Am J Enol Vitic 66:46-53.

Boubals D. 1966. Heredite de la résistance au phylloxéra radicicole chez la vigne. Ann Amelior Plantes 16:327-347.

Claridge MF and Den Hollander J. 1983. The biotype concept and its application to insect pests of agriculture. Crop Prot 2:85-95.
Corrie AM and Hoffmann AA. 2004. Fine-scale genetic structure of grape phylloxera from the roots and leaves of Vitis. Heredity 92:118-127.

Corrie AM, Buchanan G and Van Heeswijck R. 1997. DNA typing of populations of phylloxera (Daktulosphaira vitifoliae (Fitch)) from Australian vineyards. Aust J Grape Wine Res 3:50-56.

Corrie AM, Crozier RH, Van Heeswijck R and Hoffmann AA. 2002. Clonal reproduction and population genetic structure of grape phylloxera, Daktulosphaira vitifoliae, in Australia. Heredity 88:203-211.

De Benedictis JA and Granett J. 1992. Variability of responses of grape phylloxera (Homoptera, Phylloxeridae) to bioassays that discriminate between California biotypes. J Econ Entomol 85:1527-1534.

De Benedictis JA and Granett J. 1993. Laboratory evaluation of grape roots as hosts of California grape phylloxera biotypes. Am J Enol Vitic 44:285-291.

De Benedictis JA, Granett J and Taormino SP. 1996. Differences in host utilization by California strains of grape phylloxera. Am J Enol Vitic 47:373-379.

de Klerk CA. 1979. An investigation of two morphometric methods to test for the occurrence of morphologically different races of Daktulosphaira vitifoliae (Fitch) in South Africa. Phytophylactica 11:51-52.

Downie DA. 2010. Baubles, bangles, and biotypes: A critical review of the use and abuse of the biotype concept. J Insect Sci 10:176.

Downie DA, Granett J and Fisher JR. 2000. Distribution and abundance of leaf galling and foliar sexual morphs of grape phylloxera (Hemiptera: Phylloxeridae) and Vitis species in the central and eastern United States. Environ Entomol 29:979-986.

Du YP, Wang ZS, Sun QH, Zhai H and Wang ZY. 2008. Evaluation on grape phylloxera resistance in several grape varieties and rootstocks. Acta Entomol Sinica 511:33-39.

Eitle $\mathrm{M}$ and Forneck A. Comparison of bioassays to biotype grape phylloxera (Daktulosphaira vitifoliae Fitch) on Vitis ssp. Entomol Appl, submitted for publication, 2015.

Forneck A and Huber L. 2009. (A)sexual reproduction-a review of life cycles of grape phylloxera, Daktulosphaira vitifoliae. Entomol Exp Appl 131:1-10.

Forneck A, Walker MA and Merkt N. 1996. Aseptic dual culture of grape (Vitis spp.) and grape phylloxera (Daktulosphaira vitifoliae Fitch). Vitis 35:95-98.

Forneck A, Walker MA and Blaich R. 2001a. Ecological and genetic aspects of grape phylloxera Daktulosphaira vitifoliae (Hemiptera: Phylloxeridae) performance on rootstock hosts. Bull Entomol Res 91:445-451.

Forneck A, Walker MA, Blaich R, Yvon M and Leclant F. 2001b. Interaction of phylloxera (Daktulosphaira vitifoliae Fitch) with grape (Vitis spp.) in simple isolation chambers. Am J Enol Vitic 52:28-34.

Forneck A, Walker MA and Blaich R. 2001c. An in vitro assessment of phylloxera (Daktulosphaira vitifoliae Fitch) (Hom., Phylloxeridae) life cycle. J Appl Entomol 125:443-447.

Forneck A, Powell KS and Walker MA. 2015. Reblaus-Biotypen: Stand der Forschung. Der Deutsche Weinbau 25:18-21.

Forneck A, Dockner V, Mammerler R, Powell KS, Kocsis L, Papura D, Fahrentrapp J, Riaz S and Walker MA. 2016. PHYLLI - an international database for grape phylloxera (Daktulosphaira vitifoliae Fitch). Submitted to the IOBC-WPRS Bull. (15.12.2015).

Granett J, Bisabri-Ershadi B and Carey J. 1983. Life tables of phylloxera on resistant and susceptible grape rootstocks. Entomol Exp Appl 34:13-19.

Granett J, Timper P and Lider LA. 1985. Grape phylloxera (Daktulosphaira vitifoliae) (Homoptera: Phylloxeridae) biotypes in California. J Econ Entomol 78:1463-1467. 
Granett J, Goheen AC, Lider LA and White JJ. 1987. Evaluation of grape rootstocks for resistance to Type A and Type B grape phylloxera. Am J Enol Vitic 38:298-300.

Granett J, Walker MA, Kocsis L and Omer AD. 2001. Biology and management of grape phylloxera. Ann Rev Entomol 46:387-412.

Grzegorczyk W and Walker MA. 1998. Evaluating resistance to grape phylloxera in Vitis species with an in vitro dual assay culture. Am J Enol Vitic 49:17-22.

Herbert KS, Umina PA, Mitrovski PJ, Powell KS, Viduka K and Hoffmann AA. 2010. Clone lineages of grape phylloxera differ in their performance on Vitis vinifera. Bull Entomol Res 100:671-678.

Kellow AV, McDonald G, Corrie AM and Van Heeswijck R. 2002. In vitro assessment of grapevine resistance to two populations of phylloxera from Australian vineyards. Aust J Grape Wine Res 8:109-116.

King PD and Rilling G. 1985. Variations in the galling reaction of grapevines, evidence of different phylloxera biotypes and clonal reaction to phylloxera. Vitis 24:32-42.

King PD and Rilling G. 1991. Further evidence of phylloxera biotypes: Variations in the tolerance of mature grapevine roots related to the geographical origin of the insect. Vitis 30:233-244.

Kocsis L, Granett J and Walker MA. 2002. Performance of Hungarian phylloxera strains on Vitis riparia rootstocks. J Appl Entomol 126:567-571.

Korosi GA, Trethowan CJ and Powell KS. 2007. Screening for rootstock resistance to grapevine phylloxera genotypes from Australian vineyards under controlled conditions. Acta Hortic 733:159-165.

Makee H, Charbaji T, Ayyoubi Z and Idris I. 2004. Evaluating resistance of some rootstocks to grape phylloxera with in vitro and excised root testing systems. In Vitro Cell Dev B 40:225-229.

Pavloušek P. 2012. Screening of rootstock hybrids with Vitis cinerea Arnold for phylloxera resistance. Cent Eur J Biol 7:708-719.

Pelet F, Hildebrandt AC, Riker AJ and Skoog F. 1960. Growth in vitro of tissues isolated from normal stems and insect galls. Am J Bot 47:186-195.

Porten M and Huber L. 2003. An assessment method for the quantification of Daktulosphaira vitifoliae (Fitch) (Hem., Phylloxeridae) populations in the field. J Appl Entomol 127:157-162.

Powell KS and Korosi GA. 2014. 'Taking the strain' - selecting the right rootstock to protect against endemic phylloxera strains. Acta Hortic 1045:99-107.

Powell KS and Krstic M. 2015. Phylloxera: Rootstock tolerance and resistance to different genetic strains of phylloxera. Wine Vitic J 30:48-51.

Powell KS, Slattery WF, Deretic J, Herbert K and Hetherington S. 2003. Influence of soil type and climate on the population dynamics of grapevine phylloxera in Australia. Acta Hortic 617:33-41.

Powell KS, Korosi GA and Mackie AM. 2009. Monitoring grape phylloxera populations using simple non-destructive trapping systems. Acta Hortic 816:29-34.
Powell KS, Cooper PD and Forneck A. 2013. The biology, physiology and host-plant interactions of grape phylloxera Daktulosphaira vitifoliae. Adv Insect Physiol 45:159-218.

Printz YI. 1937. Contribution to the question of the changes in the virulence of phylloxera of different biotypes. Plant Protec Leningrad $12: 137-142$.

Ramming DW. 2010. Greenhouse screening of grape rootstock populations to determine inheritance of resistance to phylloxera. Am J Enol Vitic 61:234-239.

Sandström J. and Pettersson J. 1994. Amino acid composition of phloem sap and the relation to intraspecific variation in pea aphid (Acyrthosiphon pisum) performance. J Insect Physiol 40:947-955.

Singer MC. 1986. The definition and measurement of ovipostion preference in plant-feeding insects. In Insect-Plant Interactions. JR Miller and TA Miller (eds.), pp. 63-93. Springer Science+Business Media, New York.

Song GC and Granett J. 1990. Grape phylloxera (Homoptera: Phylloxerideae) biotypes in France. J Econ Entomol 83:489-493.

Stevenson AB. 1970. Strains of the grape phylloxera in Ontario with different effects on the foliage of certain grape cultivars. J Econ Entomol 63:135-138.

Sullivan V. 1996. New rootstocks stop vineyard pest for now. Calif Agr 50:7-8.

Trethowan CJ and Powell KS. 2007. Rootstock-phylloxera interactions under Australian field conditions. Acta Hortic 733:115-122.

Umina PA, Corrie AM, Herbert KS, White VL, Powell KS and Hoffmann AA. 2007. The use of DNA markers for pest managementclonal lineages and population biology of grape phylloxera. Acta Hortic 733:183-195.

Vidart MV, Mujica MV, Bao L, Duarte F, Bentancourt CM, Franco $\mathrm{J}$ and Scatoni IB. 2013. Life history and assessment of grapevine phylloxera leaf galling incidence on Vitis species in Uruguay. SpringerPlus 2:181.

Vorburger C, Lancaster M and Sunnucks P. 2003. Environmentally related patterns of reproductive modes in the aphid Myzus persicae and the predominance of two 'superclones' in Victoria. Mol Ecol 12:3493-3504.

Williams RN and Shambaugh GF. 1988. Grape phylloxera (Homoptera: Phylloxeridae) biotypes confirmed by electrophoresis and host susceptibility. Ann Entomol Soc Am 81:1-5.

Yvon M and Leclant F. 2000. Intraspecific variability in grape phylloxera (Daktulosphaira vitifoliae Fitch) in France: Development of rearing techniques. Acta Hortic 528:581-586.

Yvon M and Peros JP. 2003. Variation in aggressiveness and genetic diversity of grape phylloxera in southern France. J Int Sci Vigne Vin 37:77-84. 